\title{
关于在南疆农村区域精准投资建设的思考 一以喀什农村户户通工程为例
}

\author{
李贵祥 \\ 中国电信新疆分公司，新疆 乌鲁木齐 833000
}

[摘要] 新疆南疆区域, 幅员辽阔，气候干旱，南疆四地州农村人口占比高、基数大，经济欠发达，发展相对滞后。光网资源 覆盖有限, 通过三期普遍服务工作推进, 资源覆盖能力虽有提升, 但用户口益增长的信息化需求与资源匮乏的矛盾一时难以 解决。文章以南疆喀什地区农村户户通工程为例，以市场需求为导向，精确指引建设投入，提升资源使用效率。 [关键词]农村; FTTH 光网建设; 户户通; 五个一片；精准投资

DOI: $10.33142 / m e m . v 2 i 2.3975$ 中图分类号: F299.27 文献标识码：A

\section{Thoughts on Precision Investment in Rural Areas of Southern Xinjiang - Take Kashgar Rural Household Access Project as an Example}

\author{
LI Guixiang
}

Xinjiang Branch of China Telecom, Urumqi, Xinjiang, 833000, China

\begin{abstract}
Southern Xinjiang has a vast territory and arid climate. The proportion of rural population in the four prefectures of Southern Xinjiang is high, the base is large, the economy is underdeveloped and the development is relatively backward. The coverage of optical network resources is limited. With the promotion of the third phase of universal service, the capacity of resource coverage has been improved, but the contradiction between the growing information needs of users and the lack of resources is difficult to solve. This paper takes the rural Huhutong project in Kashi area of Southern Xinjiang as an example, takes the market demand as the guidance, accurately guides the construction investment and improves the efficiency of resource use.
\end{abstract}

Keywords: rural areas; FTTH optical network construction; Huhutong; five in a piece; precision investment

\section{引言}

为承接 “光网城市、宽带新疆” 的战略, 电信新疆公司于 2018 年正式启动 “农村户户通” 工程, 目标是将市场、 建设、装维紧密结合, 以市场需求为导向, 精确指引建设投入, 要求精准投资、快速交付、快速开通、精确评估。而 南疆作为运营商竞争的焦点区域, 是高质量发展的突破口和关键点。网络是新疆推进信息化的基础, “网络强国” 是信 息通信业的核心战略, 加强南疆信息基础设施建设, 解决南疆网络短板, 为老百姓提供用得上、用得好和用得起的信 息服务。

2014 年到 2019 年全疆通信行业XX\%的增量收入和 XX\%的移动增量用户来自南疆通信行业。一是收入增幅高于全疆, 南疆四地州通信行业收入年均增幅 XX\%, 高于全疆 XX 个百分点; 二是用户增幅高于全疆, 移动和宽带用户年均增幅分 别为 XX\%和 XX\%，分别高于全疆 XX 和 XX 个百分点。

南疆市场空间巨大, 广阔农村大有作为。整个市场呈现 “两高两低” 的特点: 一是 GDP 增速高, 为通信行业发展 创造良好环境。2013 年到 2018 年南疆四地州 GDP 年均增长 10. 2\%, 高于全疆 3 个百分点以上。二是人口占比高, 为规 模拓展农村市场奠定基础。南疆四地州人口规模超 1, 035 万, $75.6 \%$ 为农村人口, 总人口占全疆比近 42\%, 而南疆四地 州通信行业收入占比仅为 $28 \%$, 远低于人口占比。三是普及率低, 基础业务仍处于高速发展阶段。 ${ }^{[1]}$ 南疆四地州 2019 年移动用户人口普及率和宽带用户家庭普及率分别为 $82 \% 、 63 \%$, 分别低于全疆 28 和 30 多个百分点。 ${ }^{[2]}$ 四是信息化水 平低, 在新基建推动下, 信息基础设施和信息化应用方面极具潜力。一键报警、平安城市、扶贫、工业互联网、教育、 医疗、社区等方面信息化需求旺盛，南疆维稳等信息化成为刚性需求。

南疆是典型的农村型区域经济, 光网覆盖需求迫切, 截止 2019 年底, 南疆农村光端口数 95 万户, 资源覆盖率仅 为 $26.1 \%$, 远低于全疆农村资源覆盖均值; 南疆四地州资源覆盖也不均衡, 喀什覆盖率最低, 仅为 $55 \%$; 南疆光端口资 
源占有率仅为 $24 \%$, 低于全疆农村区域 $32 \%$ 占用率的均值, 其中喀什区域实战率仅为 $19 \%$ 。 ${ }^{[3]}$ 传统的先建设, 再销售的 方式形成资源利用率低的弊端。后端建设时只负责完成工程建设, 二级分光器布防是否合理, 周边是否有障碍均欠缺 考虑, 导致有资源的地方不一定有用户, 有用户的地方资源覆盖又不足, 或需要拉 $200 \mathrm{~m}$ 的入户皮线光纤才能到达用户 家, 光衰大的同时增加了维护难度。

南疆过去发展速度快, 源于人口基数大, 通信需求被释放, 但发展方式和路径粗犷, 直接表现就是用户发展价值 和质量不高, 发展不够精准。究其根源是没有精准识别市场空间, 产品没有精准匹配客户需求。

市场需求精确指引建设, 提升光端口资源实占率, 减少无效投资, 可以最大限度利用资源效率。喀什电信严格按 照五个一片 “宣传一片、受理一片、建设一片、装机一片” 的顺序, 首先预营销, 收取预存款, 确认需求后精准建设, 同时工程队再施工时一并完成入户线施工, 减少二次放线的过程, 装维人员只需要完成客户端融纤即可完成装机, 大 大提高装机效率。

\section{1 总体原则}

以“整村推进” 模式组织开展, 集中火力针对梳理出来的目标村逐一进行地毯式营销, 集中连片的住户要求百分 百上门开展销售，达到既定销售目标后方可切换战场。

\section{2 销售组织}

要求每个经营单位组织至少 2 个销售突击队, 确保具备同时在 2 个战场开展实战销售的能力, PK 赛第一组成员可 以根据人员情况适当增加突击队数量。要求每个突击队由副局长亲自挂帅, 支局长任副队长, 队员包含支局人员、五 级划小承包人、社会渠道人员、支部下沉人员等。

突击队既要有定点销售小组, 还要有机动小分队。要求每个突击队至少要有 3 个机动小分队。定点销售小组人员 构成: 销售人员 (必须具备双语能力)、受理人员 (渠道 4.0 受理)、协销人员 (负责业务登记单填写及礼品发放)。机 动小分队人员由销售人员（必须具备双语能力）、受理人员（翼销售受理）等构成。

\section{1 做足售前准备}

各经营单位要根据梳理目标村的情况制定详细作战计划, 并严格按照计划开展销售。为确保现场实战的顺利开展, 在开展营销前, 五级划小承包人要提前拜访村委会、驻村工作组领导, 递交相关网络扶贫政策文件, 取得政府部门的 支持, 报备销售计划, 同时要提前踩点, 确定现场路演摆推的地点, 确保能接电、有网络。流动营业车、桌椅、横幅、 宣传单、海报、音箱、音频广告文件、库看之家即时贴、记号笔、演示电视、礼品堆头等宣传物料准备齐全; 安装翼 销售客户端手机终端、蓝牙读卡器、业务受理单 50 份、UIM 卡 50 张等受理工具。

\section{2 做好宣传销售}

利用宣传单、海报、横幅、广播音频、住户门帖、流动营业车 LED，营造电信网络扶贫宣传，占领宣传主阵地。采 用自下而上和自上而下相结合的销售模式, 即机动小分队组员做好分工, 相互提供协同支撑。突击队的机动小分队入 户扫村, 开展地毯式销售; 五级承包人发展村级能人协助发展用户，扫村的同时五级承包人发展一村一店业务代办点。

县分局长递送扶贫方案到县政府扶贫办，争取扶贫办给予本次网络扶贫攻坚战的政策支持。支局长递送扶贫方案 到乡政府, 争取乡镇府支持。五级承包人递送扶贫方案到驻村工作组, 争取驻村工作组的支持, 充分利用集中升旗、 夜校学习等村民集中机会宣传业务, 让村领导为我们站台宣讲, 开展整村团购。

\section{3 张贴 “库看家庭” 门贴}

受理完成后, 在住户入院大门显著位置上张贴 “库看家庭” 门贴, 同时用记号笔在门贴上规整的填写标准地址编 码和服务电话, 要求服务电话统一留五级划小承包人的联系方式。

\section{4 开展每日复盘}

建立营销台账制度, 台账要求记录用户名称、安装地址、移动号码等关键信息。每个突击队在销售次日晨会上组 织复盘, 通报各机动小分队的销量, 销量多的分享经验, 销售少的总结不足, 通过不断的复盘总结提升突击队的整体 销售能力。

\section{3 网络建设工作}

网络建设是宽带业务发展的重要基础, 盘活现有资源, 建需匹配, 实现网络资源精准建设。根据市场发展目标及 资源现状, 发起建设需求, 设计单位接到县分需求后, 根据预受理用户分布进行设计, 设计必须由前端、后端副经理、 
五级划小人员签字认可方可安排施工。

预受理完成后, $X$ 天内完成受理区域的设计, $X$ 天内完成入户施工及资源录入, $X$ 天完成挂测和验收工作。交付标 准为资源系统录入且具备放装条件, 若不具备放装条件的视同为未交付。资源录入时要求严格按照统一的编码规则进 行录入, 同时保证与预销售时张贴的用户分组对应, 确保业务工单能准确匹配。由各区域资源管理岗位人员及分公司 资源管理中心人员支撑。资源交付时, 要求五级划小承包人、县分公司资源管理人员和主管后端副经理签字后方可确 认验收通过。县分公司维护站、施工单位、喀什传输分局维护站人员及时验收。

待工程建设完毕资源挂测成功后, 即可发起安装申请。工单标准资源修订由各县分公司资源管理人员负责修订, 按照工单录入的用户安装地址匹配标准九级地址, 完成后即可按照正常流程派发外线作业工单; 客户服务工程师需提 前准备装机所需的网关及机顶盒, 确保在工单到流转到工位时规定时限内完成装机。

\section{4 结束语}

通过此次攻坚活动, 2019 年, 喀什农村区域新装宽带 XX 万户, 同比增长 XX\%, 高于南疆均值和全疆均值。

南疆县域及以下人口占比超 $80 \%$, 是收入和用户规模发展的主阵地, 南疆通信行业业务普及率低, 是增量市场的主 要来源, 加快推进户户通工程, 有效提升资源利用率, 有助于推动企业进入新一轮增长, 为 “十四五” 末成为区域行 业领先企业奠定坚实基础。

\section{[参考文献]}

[1] 侯艳军, 安瓦尔・买买提明. 基于 GIS 对南疆区域城市化综合水平的差异与城市组团发展研究 [J]. 新疆师范大学学报 (自然科学版), 2011，30 (2): 24-27.

[2] 新疆统计局. 新疆统计年鉴 2019[M]. 北京: 中国统计出版社, 2019.

[3] 哈丽云. 乡村振兴视域下南疆农村人居环境优化的路径探析- - 以喀什地区 $\mathrm{S}$ 县 $\mathrm{T}$ 乡为例 $[\mathrm{J}]$. 兵团党校学 报, 2021, 11(2) : 44-48.

作者简介: 李贵祥 (1984-), 男, 毕业院校: 重庆邮电大学, 所学专业: 计算机科学与技术, 当前就职于: 中国电信 新疆分公司, 职务中级工程师。 